\title{
De novo interstitial deletion in the long arm of chromosome 11: a case report
}

\author{
L.L. Li ${ }^{1}$, H.G. Zhang ${ }^{1}$, X.G. Shao ${ }^{2}$, J.C. Gao ${ }^{3}$, H.Y. Zhang ${ }^{1}$ and R.Z. Liu' ${ }^{1}$ \\ ${ }^{1}$ Center for Reproductive Medicine, Center for Prenatal Diagnosis, \\ The First Hospital of Jilin University, Changchun, China \\ ${ }^{2}$ Dalian Municipal Women and Children's Medical Center, Dalian, China \\ ${ }^{3}$ School of Basic Medical Sciences, Jilin University, Changchun, China
}

Corresponding author: R.Z. Liu

E-mail:1rz410@126.com

Genet. Mol. Res. 15 (2): gmr.15028403

Received January 8, 2016

Accepted February 26, 2016

Published July 15, 2016

DOI http://dx.doi.org/10.4238/gmr.15028403

\begin{abstract}
The $11 \mathrm{q}$ terminal deletion disorder is a rare genetic disorder associated with numerous clinical features. A few case reports have been made about de novo interstitial deletion of chromosome 11q. However, due to the heterogeneity in size and position of the deletions, a clear genotype-phenotype correlation is not easily made. Here we report a case interstitial 20.5-Mb deletion at chromosome $11 \mathrm{q} 13.4 \mathrm{q} 21$, as confirmed by array comparative genomic hybridization. Dysmorphic features such as coarse facial features, congenital laryngomalacia, oblique inguinal hernia, higharched palate, and camptodactyly were observed in the subject. The present case broadens the spectrum of clinical findings observed in individuals with $11 \mathrm{q}$ interstitial deletion.
\end{abstract}

Key words: Interstitial deletion; Array comparative genomic hybridization; Chromosome 11; Genotype-phenotype correlation 


\section{INTRODUCTION}

Cytogenetic of chromosome 11q deletion are widely reported in previous studies (Melis et al., 2010). The 11q terminal deletion disorder or Jacobsen syndrome (JBS) is a rare genetic disorder associated with numerous dysmorphic features, and occurs in 1/100,000 live births with a female predominance of 2:1 (Sheth et al., 2014). Typical clinical characteristics of JBS include mental retardation, developmental delay, short stature, thrombocytopenia, and congenital heart defects (Bernaciak et al., 2008). Severity of clinical symptoms depends on the size of $11 \mathrm{q} 23$ deletions, which vary from 7 to $20 \mathrm{Mb}$, but can be as small as $2.9 \mathrm{Mb}$ in some cases (Sheth et al., 2014).

There have been several reports regarding interstitial deletion of chromosome 11q. In some cases, high-resolution mapping of the abnormality cannot be achieved due to limitations of conventional chromosome analysis (Melis et al., 2010). In addition, many different abnormalities have been reported in patients with varying interstitial breakpoints on $11 \mathrm{q}$ (Pivnick et al., 1996; Ikegawa et al., 1998; Meyer et al., 2000; Goumy et al., 2008).

In this case report, we describe a boy with coarse facial features, congenital laryngomalacia, oblique inguinal hernia, high-arched palate, and camptodactyly. We also review previous reports of interstitial deletion on chromosome 11q13q23.

\section{MATERIAL AND METHODS}

\section{Patients}

The boy is the firstborn to a 25-year-old mother and a 27 -year-old father who were healthy and unrelated. There was no history of miscarriage or infertility. Both parents had no family history of genetic diseases.

The baby was birthed at 36 weeks of gestation by cesarean section due to premature rupturing of the membranes. Birth weight was $2.7 \mathrm{~kg}$ and length was $48 \mathrm{~cm}$. Dysmorphic features such as coarse facial features, congenital laryngomalacia, oblique inguinal hernia, high-arched palate, and camptodactyly were observed in the subject. He also demonstrated reduced autonomic activities, feeding difficulties, cardiovascular dysfunction, rickets, congenital heart disease, encephalodysplasia, and immune dysfunction.

The study was approved by the Ethics Committee of the First Hospital of Jilin University, Changchun, China, and written informed consent was obtained from the parents.

\section{Cytogenetic analysis}

Peripheral blood $(0.5 \mathrm{~mL})$ from the boy was collected into sterile tubes containing 30 $\mathrm{U} / \mathrm{mL}$ heparin, and G-banding was performed using cultured peripheral blood lymphocytes (Zhang et al., 2013). We analyzed 20 metaphases, and chromosomal abnormalities were described according to the International System for Human Cytogenetic Nomenclature (2009).

\section{Array comparative genomic hybridization (CGH)}

Genomic DNA was isolated from peripheral blood using a QIAGEN QIAamp DNA Blood mini kit. Control DNA was obtained directly from Promega (G1471/G1521). The array 
CGH was performed according to manufacturer instructions. Array experiment and analysis was performed as previously described (Dong et al., 2014).

\section{RESULTS}

Conventional cytogenetic analysis of the proband showed 46 chromosomes, with deletion on the long arm of chromosome 11 (Figure 1). However, the karyotypes of both parents were normal.


13

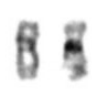

19

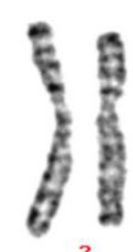

2



7



14

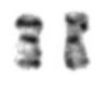

20



3



9



15

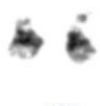

21

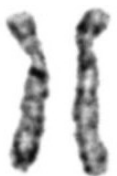

4



10



16



22

11

17

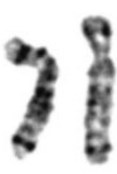

5
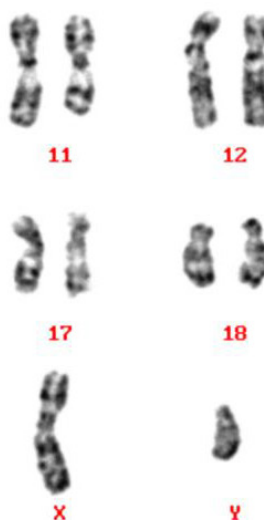

Figure 1. Karyotype of the proband. Autosomal chromosomes are labeled 1 through 22, and sex chromosomes are indicated by $\mathrm{X}$ and $\mathrm{Y}$.

The proband karyotype was 46,XY, del(11)(q13.4q21); interstitial deletion of chromosome 11q was confirmed by array CGH. Array CGH results indicated that the deletion encompassed approximately $20.50 \mathrm{Mb}$ of chromosome 11q (Figure 2). The deleted segment encoded 115 HGNC (Hugo Gene Nomenclature Committee) genes and 11 OMIM (Online Mendelian in Man) genes.

\section{DISCUSSION}

Chromosome 11q deletions are widely reported in previous literatures. Terminal deletions, also known as Jacobsen syndrome, are frequently described (Melis et al., 2010). Clinical phenotypes of this syndrome are severely debilitating, and frequently result in deaths (Sachdeva et al., 2010). Chromosomal deletions with break point at q23 have been reported, with variable break points between 11q11 and 11qter (Puvabanditsin et al., 2001). However, 


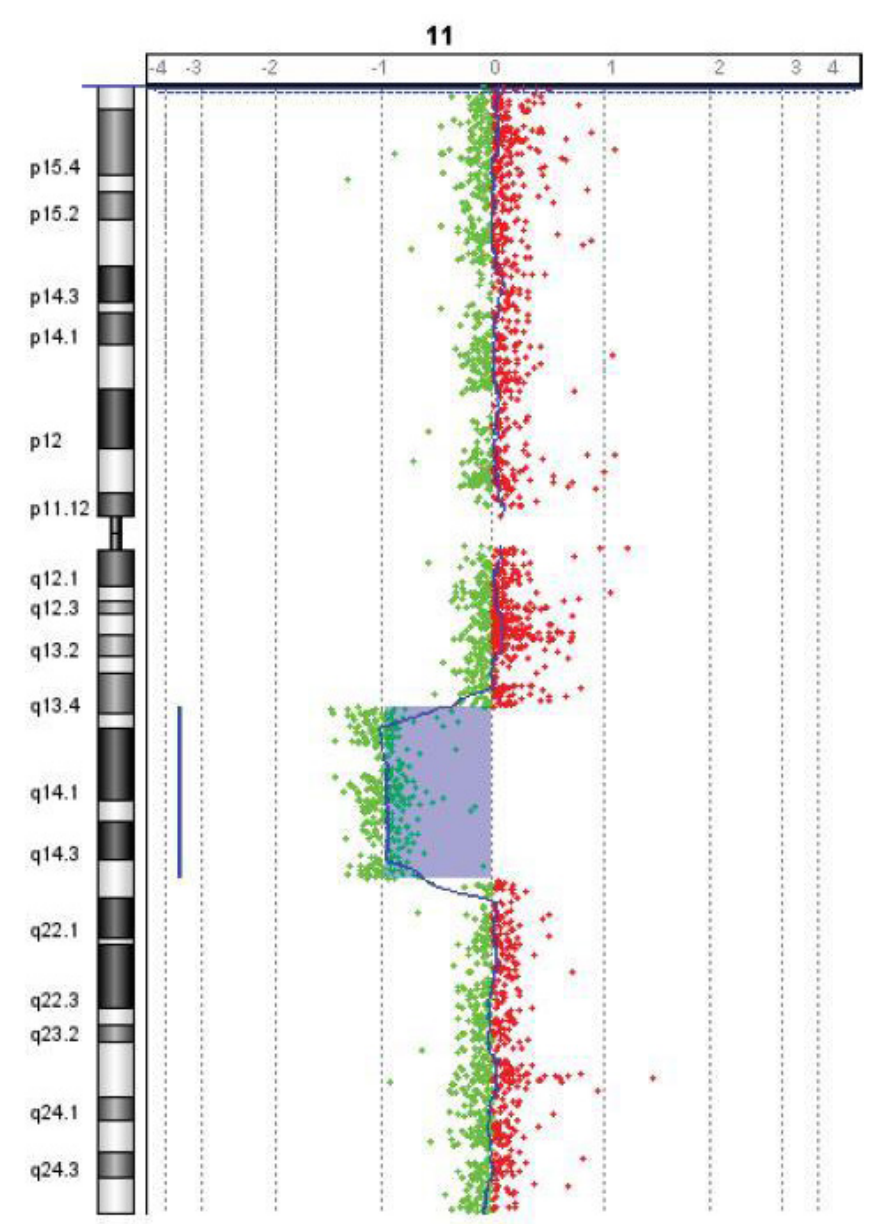

Figure 2. Array CGH showing a 20.5-Mb deletion at 11q13.4q21. The region of chromosomal deletion is indicated by the gray area.

interstitial deletions that do not affect terminal ends are associated with more variable and less severe disease phenotypes (Sachdeva et al., 2010). As these types of deletions are extremely rare, the genotype-phenotype correlations in interstitial deletions are unknown (Yelavarthi et al., 2015).

The first case of chromosome 11q interstitial deletion was described by Taillemite et al. (1975). Horelli-Kuitunen et al. (1999) reviewed that de novo interstitial deletions of chromosome 11q have been reported in nine patients, and additionally reported a case of interstitial deletion from 11q21 to q22.3. Nacinovich et al. (2014) reviewed that 34 cases with different breakpoints spanning from bands $11 \mathrm{q} 13$ to $11 \mathrm{q} 23$ were previously described, and simultaneously reported a de novo interstitial deletion of chromosome from 11q14.3 to q22.3. Yelavarthi et al. (2015) reported five individuals with de novo 11q22.2q23.3 deletions that presented developmental delays. Main clinical manifestations and deleted regions of these cases are shown in Table 1. 
Table 1. Main clinical manifestations of the cases with interstitial deletion from 11q13 to q23.2.

\begin{tabular}{|c|c|c|c|c|}
\hline Year & Accumulative cases & \begin{tabular}{|l} 
Main clinical manifestations \\
\end{tabular} & Deleted region (range) & Reference \\
\hline 1975 & 1 & Mild facial deformity, broad skull and mental retardation & $11 \mathrm{q} 14-\mathrm{q} 21$ & Taillemite et al. (1975) \\
\hline 1999 & 10 & $\begin{array}{l}\text { Trigonocephaly, hypertelorism, low-set or malformed ears, micrognathia, coloboma iris defect, and congenital } \\
\text { heart defects } \\
\text { Less frequent findings included mental retardation, postnatal growth failure, and renal and digital anomalies, } \\
\text { pseudoachondroplasia }\end{array}$ & $11 q 13-q 23$ & Horelli-Kuitunen et al. (1999) \\
\hline 2014 & 35 & $\begin{array}{l}\text { Major malformation: trigonocephaly, dolichocephaly, brain anomalies, kidney anomalies, submucous cleft } \\
\text { palate, heart defect, genital anomalies, uni/bilateral club foot, iris and chorioretinal coloboma, retinal } \\
\text { dysgenesis//bilateral exudative vitreoretinopathy } \\
\text { Minor anomalies: prominent forehead, round face, uni/bilateral eyelids ptosis, up-slanted palpebral fissures, } \\
\text { periorbital fullness, epi/telecanthus, hypertelorism, ear anomalies, nose anomalies, full cheeks, high arched } \\
\text { palate, mouth anomalies, micro/retrognathia, minor skeletal anomalies }\end{array}$ & $11 \mathrm{q} 13-\mathrm{q} 23.2$ & Nacinovich et al. (2014) \\
\hline 2015 & 40 & Somewhat mild intellectual disability and dysmorphism & $\mathrm{q} 22.2-\mathrm{q} 22.3$ & Yelavarthi et al. (2015) \\
\hline & 41 & Coarse facial features, high-arched palate, congenital laryngomalacia, oblique inguinal hernia, camptodactyly & $\frac{4-2.2-4253}{11 \mathrm{q} 13.4-\mathrm{q} 21}$ & Present case \\
\hline
\end{tabular}

In this study, we reported a de novo deletion of chromosome 11q13q21 in a 3-monthold boy by cytogenetic analysis (Figure 1). Array CGH revealed a 20.5-Mb deletion (from nt $74,465,008$ to nt 94,962,697) in 11q13.4q21 (Figure 2). Notable features including coarse facial features, congenital laryngomalacia, oblique inguinal hernia, high-arched palate, and camptodactyly were observed. He also demonstrated reduced autonomic activities, feeding difficulties, cardiovascular dysfunction, rickets, congenital heart disease, encephalodysplasia, and immune dysfunction. The high-arched palate that we observed in this case was also described in another case by Guć-Sćekić et al. (1989). Facial dysmorphism and camptodactyly in our case was observed by Chen et al. (2004) in a patient with the karyotype 46,XX, $\operatorname{del}(11)(q 24.1)$. It is difficult to define a distinctive phenotype in 11q partial monosomy as the phenotype depends on haploinsufficient genes. Furthermore, complex gene-gene and gene-environment interactions also play a role in disease pathogenesis (Nacinovich et al., 2014). Therefore, further studies need to be conducted to determine the genotype-phenotype correlations in detail.

\section{CONCLUSIONS}

In summary, due to the heterogeneity in size and position of the deletions, a clear genotype-phenotype correlation of interstitial deletions of chromosome 11 is not clear. Our patient has a $20.5-\mathrm{Mb}$ deletion within the 11q13.4-q21 region, which is accompanied by additional phenotypic features. The present case broadens the spectrum of clinical findings observed in individuals with 11q interstitial deletions.

\section{Conflicts of interest}

The authors declare no conflict of interest.

\section{ACKNOWLEDGMENTS}

We would like to thank the patient and his parents for participating in this study. We express our sincere gratitude to all the staff of the Genetics Laboratory, Center for Prenatal Diagnosis, First Hospital, Jilin University, for their excellent work. Research supported by the National Natural Science Fund (\#81471515). 


\section{REFERENCES}

Bernaciak J, Szczałuba K, Derwińska K, Wiśniowiecka-Kowalnik B, et al. (2008). Clinical and molecular-cytogenetic evaluation of a family with partial Jacobsen syndrome without thrombocytopenia caused by an approximately $5 \mathrm{Mb}$ deletion del(11)(q24.3). Am. J. Med. Genet. A. 146A: 2449-2454.http://dx.doi.org/10.1002/ajmg.a.32490

Chen CP, Chern SR, Chang TY, Tzen CY, et al. (2004). Prenatal diagnosis of the distal 11q deletion and review of the literature. Prenat. Diagn. 24: 130-136.http://dx.doi.org/10.1002/pd.802

Dong Y, Chen SC, Yu XW, Fadlalla E, et al. (2014). Birth of a healthy child by a woman with inherited Xq duplications who had experienced stillbirths. Genet. Mol. Res. 13: 4573-4578.http://dx.doi.org/10.4238/2014.June.17.9

Goumy C, Gouas L, Tchirkov A, Roucaute T, et al. (2008). Familial deletion 11q14.3-q22.1 without apparent phenotypic consequences: a haplosufficient $8.5 \mathrm{Mb}$ region. Am. J. Med. Genet. A. 146A: 2668-2672.http://dx.doi.org/10.1002/ ajmg.a.32511

Guć-Sćekić M, Pilić-Radivojević G, Mrdjenović G and Djurić M (1989). Interstitial deletion of 11q. J. Med. Genet. 26: 205-206.http://dx.doi.org/10.1136/jmg.26.3.205

Horelli-Kuitunen N, Gahmberg N, Eeva M, Palotie A, et al. (1999). Interstitial deletion of bands 11q21 $\rightarrow 22.3$ in a threeyear-old girl defined using fluorescence in situ hybridization on metaphase chromosomes. Am. J. Med. Genet. 86: 416-419.http://dx.doi.org/10.1002/(SICI)1096-8628(19991029)86:5<416::AID-AJMG4>3.0.CO;2-S

Ikegawa S, Ohashi H, Hosoda F, Fukushima Y, et al. (1998). Pseudoachondroplasia with de novo deletion [del(11) (q21q22.2)]. Am. J. Med. Genet. 77: 356-359.http://dx.doi.org/10.1002/(SICI)1096-8628(19980605)77:5<356::AIDAJMG3>3.0.CO;2-L

Melis D, Genesio R, Cozzolino M, Del Giudice E, et al. (2010). An emerging phenotype of proximal 11q deletions. Eur. J. Med. Genet. 53: 340-343.http://dx.doi.org/10.1016/j.ejmg.2010.07.010

Meyer MF, Gerresheim F, Pfeiffer A, Epplen JT, et al. (2000). Association of polycystic ovary syndrome with an interstitial deletion of the long arm of chromosome 11. Exp. Clin. Endocrinol. Diabetes 108: 519-523.http://dx.doi. org $/ 10.1055 / \mathrm{s}-2000-11023$

Nacinovich R, Villa N, Redaelli S, Broggi F, et al. (2014). Interstitial 11q deletion: genomic characterization and neuropsychiatric follow up from early infancy to adolescence and literature review. BMC Res. Notes 7: 248.http:// dx.doi.org/10.1186/1756-0500-7-248

Pivnick EK, Velagaleti GV, Wilroy RS, Smith ME, et al. (1996). Jacobsen syndrome: report of a patient with severe eye anomalies, growth hormone deficiency, and hypothyroidism associated with deletion 11 (q23q25) and review of 52 cases. J. Med. Genet. 33: 772-778.http://dx.doi.org/10.1136/jmg.33.9.772

Puvabanditsin S, Garrow E, Zia-Ullah MO, Supavekin S, et al. (2001). Monosomy 11Q: report of new phenotypic manifestations. Genet. Couns. 12: 283-286.

Sachdeva R, Sears JE and Rychwalski PJ (2010). A novel case of bilateral high myopia, cataract, and total retinal detachment associated with interstitial 11q deletion. Ophthalmic Genet. 31: 84-88.http://dx.doi.org/10.3109/13816811003628833

Sheth FJ, Datar C, Andrieux J, Pandit A, et al. (2014). Distal deletion of chromosome 11q encompassing Jacobsen syndrome without platelet abnormality. Clin. Med. Insights. Pediatr. 8: 45-49.http://dx.doi.org/10.4137/CMPed. $\underline{\mathrm{S} 18121}$

Taillemite JL, Morlier BG and Roux C (1975). [Interstitial deletion of the long arm of one 11 chromosome]. Ann. Genet. 18: 61-63.

Yelavarthi K, Cabral H, Wilson GN, Rohena L, et al. (2015). Partial monosomy of 11q22.2q22.3 including the SDHD gene in individuals with developmental delay. Am. J. Med. Genet. A. 167A: 695-700.http://dx.doi.org/10.1002/ ajmg.a.36956

Zhang HG, Zhang ZB, Wang RX, Yu Y, et al. (2013). Male infertility in Northeast China: molecular detection of Y chromosome microdeletions in azoospermic patients with Klinefelter's syndrome. Genet. Mol. Res. 12: 4972-4980. http://dx.doi.org/10.4238/2013.October.24.9 